\title{
Childhood Separation Anxiety and the Risk of Subsequent Psychopathology: Results from a Community Study
}

\author{
Tanja M. Brückl ${ }^{a}$ Hans-Ulrich Wittchen ${ }^{a, b}$ Michael Höfler ${ }^{a, b}$ \\ Hildegard Pfister $^{\mathrm{a}}$ Silvia Schneider ${ }^{\mathrm{c}}$ Roselind Lieb $^{\mathrm{a}}$ \\ ${ }^{a}$ Department of Clinical Psychology and Epidemiology, Max Planck Institute of Psychiatry, Munich, and \\ ${ }^{b}$ Department of Clinical Psychology and Psychotherapy, Technical University of Dresden, Dresden, Germany; \\ ${ }^{\mathrm{c}}$ Department of Psychology, University of Basel, Basel, Switzerland
}

\section{Key Words \\ Separation anxiety disorder - Separation anxiety \\ hypothesis - Panic disorder - Developmental \\ psychopathology $\cdot$ Childhood disorder}

\begin{abstract}
Objective: To examine the association between separation anxiety disorder (SAD) and mental disorders in a community sample and to evaluate whether separation anxiety is specifically related to panic disorder with and without agoraphobia. Method: The data come from a 4year, prospective longitudinal study of a representative cohort of adolescents and young adults aged 14-24 years at baseline in Munich, Germany. The present analyses are based on a subsample of the younger cohort that completed baseline and two follow-up investigations $(n=1,090)$. DSM-IV diagnoses were made using the Munich Composite International Diagnostic Interview. Cox regressions with time-dependent covariates were used to examine whether prior SAD is associated with an increased risk for subsequent mental disorders. Results: Participants meeting DSM-IV criteria for SAD were at an increased risk of developing subsequent panic disorder with agoraphobia (PDAG) ( $\mathrm{HR}=18.1,95 \% \mathrm{Cl}=5.6-58.7)$, specific phobia $(\mathrm{HR}=2.7,95 \% \mathrm{Cl}=1.001-7.6)$, generalized anxiety disorder $(\mathrm{HR}=9.4,95 \% \mathrm{Cl}=1.8-48.7)$, ob-
\end{abstract}

sessive-compulsive disorder $(\mathrm{HR}=10.7,95 \% \mathrm{Cl}=1.7$ 66.1), bipolar disorder ( $\mathrm{HR}=7.7,95 \% \mathrm{Cl}=2.8-20.8)$, pain disorder ( $\mathrm{HR}=3.5,95 \% \mathrm{Cl}=1.3-9.1)$, and alcohol dependence $(\mathrm{HR}=4.7,95 \% \mathrm{Cl}=1.7-12.4)$. Increased hazard rates for PDAG ( $\mathrm{HR}=4.2,95 \% \mathrm{Cl}=1.4-12.1)$, bipolar disorder type II ( $\mathrm{HR}=8.1,95 \% \mathrm{Cl}=2.3-27.4)$, pain disorder $(\mathrm{HR}=1.9,95 \% \mathrm{Cl}=1.01-3.5)$, and alcohol dependence ( $\mathrm{HR}=2.1,95 \% \mathrm{Cl}=1.1-4$.) were also found for subjects fulfilling subthreshold SAD. Conclusions: Although revealing a strong association between SAD and PDAG, our results argue against a specific SAD-PDAG relationship. PDAG was neither a specific outcome nor a complete mediator variable of SAD.

Copyright (C) 2007 S. Karger AG, Basel

\section{Introduction}

Separation anxiety disorder (SAD) has mainly been conceptualized as a specific precursor of adult panic disorder with and without agoraphobia [1]. Research in this area goes back to Klein's [2] 'separation anxiety hypothesis' proposing a specific link between SAD and adult panic disorder with agoraphobia (PDAG) $[2,3]$. Klein assumed that panic is qualitatively different from other anxiety disorders and that these two conditions can be distinguished by a history of childhood SAD. Stimulated

\section{KARGER}

Fax +4161306 1234 E-Mail karger@karger.ch www.karger.com 
by Bowlby's [4] work on attachment, Klein further hypothesized that SAD and PDAG result from a biologic dysregulation of the innate attachment system controlling an infant's response to separation from the caregiver in order to ensure the closeness of the helpless infant to the caregiver [5].

Influenced by Klein's concept, the DSM-III established SAD as a specific predisposing factor for adult PDAG in the nomenclature [6]. Since then, a number of studies have provided evidence that SAD is related to PDAG in adulthood; however, a number of questions remain regarding this link. Specifically, not all previous studies have been able to confirm the postulated specificity between SAD and PDAG. Evidence concluding that there is a specific association comes primarily from studies in which PDAG patients were compared with healthy controls [7-9], which cannot confirm specificity. However, studies using controls affected by other mental disorders have argued against specificity or confirmed it only for females [10,11]. For example, higher rates of SAD have been observed among PDAG patients, as well as those with other mental disorders [12-16]. Silove et al. [17], using the dimensional Separation Anxiety Symptom Inventory (SASI), found that patients with PDAG and patients with generalized anxiety disorder (GAD) did not differ in SASI scores, with both having higher SASI scores than healthy controls. Another clinical study conducted by Lipsitz et al. [18] suggested that SAD might be a vulnerability marker for multiple anxiety disorders rather than for PDAG alone. Also a more recent 7.4-year follow-up of children who had received treatment for anxiety disorders reported that children with prior SAD had, compared to those with other anxiety diagnoses, more anxiety disorders in general but not specifically PDAG [19].

Previous research has also revealed mixed findings that appear to relate to methodological issues. Only few studies [20-24] have examined the relationship between SAD and other mental disorders in nonclinical samples. Studies using nonclinical convenience samples which are not representative of the community as a whole [20-22] have shown inconsistent results regarding the specificity between SAD and PDAG. While those with a dimensional measure of SAD, the SASI, found evidence for the separation anxiety hypothesis $[20,21]$, those with a categorical approach did not [22]; in the latter study, a retrospective SAD diagnosis was associated with posttraumatic stress disorder (PTSD) and GAD but not with PDAG [22].

Although not specifically testing the separation anxiety hypothesis, two studies have investigated the outcome of
SAD in randomly drawn population samples [23, 24]. In one of these studies, SAD predicted simple phobia but not any other anxiety or depressive disorder [23]. In the other study, examining the short-term outcomes of SAD in a community sample of twins, SAD predicted overanxious disorder and depression [24].

In sum, these findings collectively suggest that SAD might carry a risk for several adult anxiety disorders rather than for PDAG alone. However, it remains unknown whether SAD is associated with mental disorders other than anxiety disorders independently of PDAG. In this study, we examined the association between SAD and a wide range of mental disorders in a large general population sample which is less likely to be biased in terms of help-seeking behavior and selection effects.

\section{Subjects and Methods}

\section{Sample}

The data come from the Early Developmental Stages of Psychopathology study (EDSP). The EDSP was designed as a prospective survey to collect data on prevalence and incidence, familial and other risk factors, comorbidity, and course of mental disorders in a representative sample of originally 3,021 individuals $14-24$ years of age. The study consists of a baseline investigation, two follow-up investigations, and an independent parent survey. Because SAD was assessed only for the younger cohort, this paper is restricted to those respondents who were between 14 and 17 years old at baseline and who completed all three waves of data collection $(n=1,090)$. Detailed descriptions of the EDSP design and field procedures are reported elsewhere [25, 26].

The EDSP builds on a random population sample from the 1994 government population registers of residents in Munich, Germany. As the study was designed with special interest in the early developmental stages of psychopathology, the 14- to 15-year-olds were sampled at twice the probability of the 16- to 21-year-olds, and the 22- to 24-year-olds were sampled at half the probability of the 16- to 21-year-olds. Details about the sampling, representativeness, and sociodemographic characteristics of the whole EDSP sample have been presented $[25,26]$. Briefly, at baseline the response rate among the 14 - to 17 -year-olds was $74.3 \%(n=1,395)$. Two follow-up assessments were completed, covering an overall period of 3-4 years. The first follow-up study was conducted an average of 19.7 months (range $=15-25.6$ months) and the second follow-up study an average of 42 months (range = 34-50 months) after the baseline investigation. Of the 1,395 14- to 17-year-olds who took part in the baseline investigation, $88 \%$ completed the first follow-up (T1; $\mathrm{n}=1,228)$, and $84 \%$ completed the second follow-up (T2; $n=1,169)$. At baseline, most of the 14- to 17-year-olds were attending school (89\%) and living with their parents (98\%). About $10 \%$ were in job training. The majority were classified as belonging to the middle class $(61.4 \%)$. Sociodemographic sample characteristics reflect well the respective distribution in the total population of adolescents in the study area (Munich, Germany). 


\section{Diagnostic Assessment}

Diagnostic assessments in the baseline and the two follow-up investigations of the respondents were based on the computer-assisted personal version of the Munich Composite International Diagnostic Interview (M-CIDI), which allows for the assessment of symptoms, syndromes, and diagnoses of 48 mental disorders according to the DSM-IV along with information about onset, duration, severity, and psychosocial impairment (DIA-X/M-CIDI) [27]. Diagnoses were obtained with the M-CIDI/DSM-IV algorithms. Reliability and validity of the M-CIDI, along with descriptions of the M-CIDI format and coding conventions, have been reported in detail elsewhere [28-30]. For social and specific phobia, we also report subthreshold cases not meeting the impairment criterion.

At baseline, we used the lifetime version of the M-CIDI. At each follow-up, the M-CIDI interval (and 12-month) version was applied. In all assessments, the M-CIDI was supplemented by a separate respondents' booklet that included several scales and questionnaires for assessing psychological constructs that were relevant to our study. At all assessment stages, interviews were conducted by a total of 57 clinical interviewers, mostly graduated psychologists; all interviewers had prior experience with clinical interviews, went through the standard WHO CIDI program and practiced interviews under supervision.

Most interviews were carried out in the homes of the respondents. A detailed overview of the constructs and assessment methods used has been presented [31, 32].

\section{Separation Anxiety Disorder}

SAD was assessed with the M-CIDI anxiety module according to DSM-IV criteria as recalled by adolescent respondents at T1. This module contains a series of questions referring to the presence of separation anxiety between age 5 and age 14. It assesses whether (a) at least 3 or more out of 8 separation anxiety symptoms (e.g. repeated nightmares involving the theme of separation) required for DSM-IV criterion A were present; (b) the symptoms had a duration of at least 4 weeks (criterion B); (c) the symptoms occurred before age 18 (criterion $\mathrm{C}$ ); (d) the symptoms caused clinically significant impairment (criterion D). For subjects indicating at least 3 SAD symptoms, we also assessed the ages at which SAD symptoms occurred for the first and for the last time. The M-CIDI algorithms allow the subdivision of the following exclusive diagnostic groups.

(a) 'Symptomatic' SAD: the subject reports at least $1 \mathrm{SAD}$ symptom, but does not meet 'subthreshold' or full diagnostic criteria for SAD.

(b) 'Subthreshold' SAD: the subject falls short of the full mandatory diagnostic criteria by 1 criterion; for instance, he/she meets DSM-IV criterion A (at least 3 symptoms), criterion B (onset before age 18), and one of the remaining criteria $\mathrm{C}$ (duration) or D (impairment). The majority of the cases in this group did not meet the impairment criterion.

(c) 'Threshold' SAD: the M-CIDI/DSM-IV criteria for SAD are met (criteria A, B, C, and D).

\section{Statistical Analyses}

Data were weighted to consider different sampling probabilities as well as nonresponse at baseline and first follow-up according to sex, age, and place of residence. Analyses were performed with the Stata software package [33] and applying the Huber-White sand- wich matrix for weighted data [34]. The data from baseline and the two follow-up assessments were combined, providing lifetime data until the age at the last interview (maximum $=21$ years). Cumulative lifetime incidences were calculated by aggregating lifetime baseline (T0) and follow-up incidence information (T0-T2). Using these cumulative lifetime incidences of DSM-IV mental disorders, lifetime comorbidities between DSM-IV mental disorders and SAD were analyzed. Here, odds ratios (ORs) were calculated as measures of strength of associations. All associations were adjusted for age and sex [35].

Temporally directed associations with the onset of a respective outcome disorder (Y) like panic disorder were assessed through Cox regressions with time-dependent (here, time $=$ age) covariates stratified by sex and age cohort (the latter indicates that different curves are estimated within the strata before assessing differences [36]). Two different kinds of covariates were calculated. X(t) denotes the index disorder (e.g. separation anxiety) and is coded as 1 if the condition $\mathrm{X}$ had ever been present until the age of $\mathrm{t}-1$ and otherwise coded as 0 . Second, control variables for $X$ were calculated in order to adjust the baseline risk for the onset of $\mathrm{Y}$ in the groups with and without the disorder $\mathrm{X}$ (at a fixed age $\mathrm{t}$ ) according to other disorders that preceded the onset of $\mathrm{X}$. This approach was used to obtain hazard ratios (HRs) that were hopefully closer to the interesting causal effects than were the crude HRs [37]. For that purpose, a control Cont $(\mathrm{t})$ was coded among noncases $(\mathrm{X}=0)$ as 1 if the control disorder was present and if it preceded the median age at onset of $\mathrm{X}$ in the total sample within the respective age cohort (two cohorts had, therefore, been defined: participants between 17-19 years of age at T2 and those between 20-21 years of age at T2) or else as 0 . Among the affected cases $(\mathrm{X}=1)$, Cont $(\mathrm{t})$ was coded as 1 if the control disorder was present before age $t$ and if it preceded the onset of $\mathrm{X}$; as missing if the ages of onset of both conditions were equal, and as 0 in all other cases. Using $\mathrm{k}-1$ variables of the $\mathrm{X}$ kind at once allowed assessment of mediators for the association between e.g. $X_{1}$ and $Y$. This assessment was done by comparing the HRs between $\mathrm{X}_{1}$ and $\mathrm{Y}$ in (a) the model where the other disorders were coded as controls, i.e. Cont $_{1}(\mathrm{t}), \ldots$ Cont $_{\mathrm{k}-1}(\mathrm{t})$, and (b) the model where the other disorders were coded as index disorders, i.e. $\mathrm{X}_{2}(\mathrm{t}), \ldots \mathrm{X}_{\mathrm{k}}(\mathrm{t})$. Because we did not have age-of-onset information for symptomatic SAD, these analyses were conducted only for subthreshold and threshold SAD.

\section{Results}

\section{Lifetime Prevalence of SAD}

Table 1 shows the prevalence of different diagnostic levels of SAD in the total sample. The lifetime prevalence of DSM-IV SAD was 1.8\%. $17.7 \%$ of the threshold cases reported a current or past year SAD and 58.8\% indicated that the most recent occurrence of SAD was within the past 4 years; $17.6 \%$ said it was longer than 8 or 9 years ago.

A total of $9.5 \%$ fulfilled study criteria for subthreshold SAD. $11.1 \%$ of the subthreshold cases met SAD criteria currently or within the past year. $31.1 \%$ reported that the 


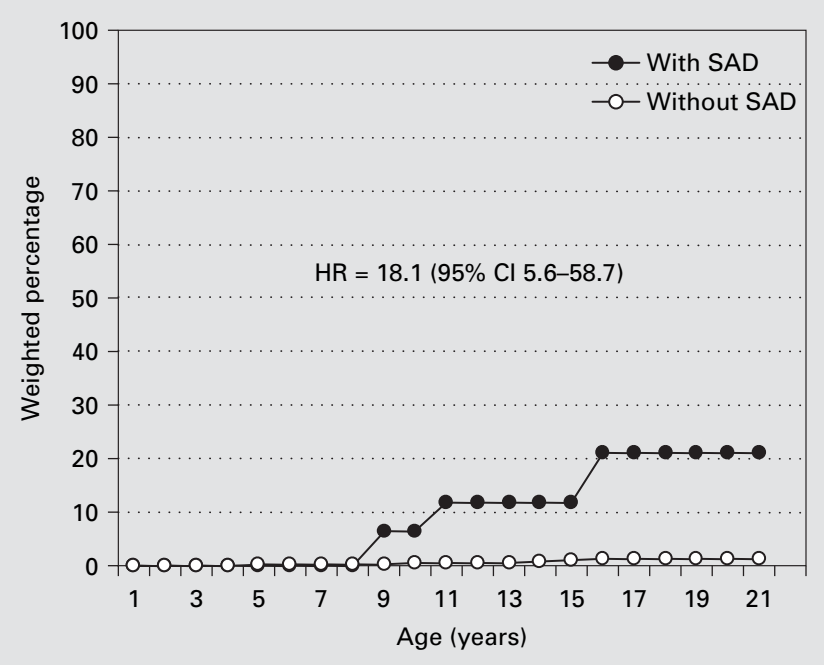

Fig. 1. Cumulative lifetime incidence of panic disorder with or without agoraphobia by prior DSM-IV SAD. HR is adjusted for age and sex.

Table 1. Lifetime prevalence of retrospectively assessed SAD in the total sample $(\mathrm{n}=1,090)$

\begin{tabular}{lrcc}
\hline & \multicolumn{3}{c}{ Lifetime prevalence } \\
\cline { 2 - 4 } & $\mathrm{n}$ & $\% \mathrm{w}$ & $95 \% \mathrm{CI}$ \\
\hline Total & & & \\
No SAD symptoms & 888 & 81.0 & $78.2-83.4$ \\
SAD symptoms & 86 & 7.8 & $6.0-9.7$ \\
'Subthreshold' SAD & 99 & 9.5 & $7.7-11.6$ \\
DSM-IV SAD & 17 & 1.8 & $1.0-3.0$ \\
Men & & & \\
No SAD symptoms & 492 & 86.4 & $8.2-89.3$ \\
SAD symptoms & 32 & 5.3 & $3.6-7.6$ \\
'Subthreshold' SAD & 36 & 7.0 & $4.9-9.8$ \\
DSM-IV SAD & 5 & 1.3 & $0.4-3.6$ \\
Women & & & \\
No SAD symptoms & 396 & 75.4 & $71.2-79.2$ \\
SAD symptoms & 54 & $10.3 *$ & $7.8-13.5$ \\
'Subthreshold' SAD & 63 & $12.1 *$ & $9.3-15.4$ \\
DSM-IV SAD & 12 & 2.2 & $1.1-4.1$ \\
\hline
\end{tabular}

$\% \mathrm{w}=$ Weighted percentages. The gender difference is significant at $* \mathrm{p}<0.05$. The asterisks indicate the group with the higher rate. ORs for females versus males are $1.8(95 \% \mathrm{CI}=1.1-2.9)$ for SAD at the subthreshold level and $2.1(95 \% \mathrm{CI}=1.2-3.4)$ for SAD at the symptomatic level versus the comparison group 'no SAD symptoms'. most recent occurrence of SAD happened within the past 4 years and $13.1 \%$ reported that it dated back to at least 10 years.

A total of $7.8 \%$ of the sample reported at least $1 \mathrm{SAD}$ symptom without fulfilling subthreshold or full criteria for SAD. Symptomatic and subthreshold SAD were more common in females than in males, whereas no gender difference was found for DSM-IV SAD.

\section{Lifetime Comorbidity of SAD with Other DSM-IV Mental Disorders}

Table 2 indicates a considerable degree of lifetime comorbidity between SAD and other mental disorders and an increase in the associations by level of SAD. Specifically, threshold cases had, compared to symptomatic cases, significantly higher odds of developing panic attack $(\mathrm{OR}=5.5,95 \% \mathrm{CI}=1.4-21.1), \mathrm{PDAG}(\mathrm{OR}=12.6,95 \%$ $\mathrm{CI}=1.9-80.6)$, any affective disorder $(\mathrm{OR}=7.4,95 \%$ $\mathrm{CI}=2.1-26.2)$, and any bipolar disorder $(\mathrm{OR}=13.7,95 \%$ $\mathrm{CI}=2.0-94.7)$. Compared to subjects with subthreshold $\mathrm{SAD}$, subjects with threshold SAD were more likely to meet criteria for panic attack $(\mathrm{OR}=4.3,95 \% \mathrm{CI}=1.2$ 14.7), $\mathrm{PDAG}(\mathrm{OR}=9.1,95 \% \mathrm{CI}=1.8-44.8), \mathrm{GAD}$ $(\mathrm{OR}=13.5,95 \% \mathrm{CI}=1.001-180.4), \mathrm{PTSD}(\mathrm{OR}=19.2$, $95 \%$ CI 1.5-240.6), any affective disorder (OR $=3.9,95 \%$ $\mathrm{CI}=1.2-13.0)$, any bipolar disorder $(\mathrm{OR}=6.1,95 \%$ $\mathrm{CI}=1.3-27.3)$, and any illegal substance use disorder $(\mathrm{OR}=6.4,95 \% \mathrm{CI}=1.009-40.2)$. ORs did not differ between symptomatic and subthreshold SAD.

\section{Prior SAD and Subsequent Mental Disorders}

Anxiety Disorders. The strongest association was found between prior threshold SAD and subsequent PDAG (fig. 1). Subjects with threshold SAD were, compared to the remaining subjects, also more likely to develop subsequent specific phobia $(\mathrm{HR}=2.7,95 \% \mathrm{CI}=1.001-7.6)$, $\operatorname{GAD}(\mathrm{HR}=9.4,95 \% \mathrm{CI}=1.8-48.7), \operatorname{PTSD}(\mathrm{HR}=12.7$, $95 \% \mathrm{CI}=3.1-51.8)$, and obsessive-compulsive disorder $(\mathrm{OCD})(\mathrm{HR}=10.7,95 \% \mathrm{CI}=1.7-66.1)$. Threshold SAD predicted neither agoraphobia without panic disorder $(\mathrm{HR}=1.4,95 \% \mathrm{C}=0.1-9.1)$ nor social phobia $(\mathrm{HR}=3.2$; $95 \% \mathrm{CI}=0.8-12.1)$. Subjects with subthreshold SAD had, compared to those without threshold or subthreshold $\mathrm{SAD}$, a higher risk of subsequent PDAG $(\mathrm{HR}=4.2,95 \%$ $\mathrm{CI}=1.4-12.1)$ but not for other anxiety disorders.

Affective Disorders. Subjects with threshold SAD had, compared to the remaining subjects, an elevated risk of subsequent bipolar type I $(\mathrm{HR}=6.2,95 \% \mathrm{CI}=1.7-21.6)$ and bipolar type II disorder $(\mathrm{HR}=8.5,95 \% \mathrm{CI}=1.6$ $43.5)$ but not of major depression $(\mathrm{HR}=2.1,95 \% \mathrm{CI}=$ 
Table 2. Lifetime comorbidities between SAD and other mental disorders $(n=1,090)$

\begin{tabular}{|c|c|c|c|c|c|c|c|c|c|c|}
\hline $\begin{array}{l}\text { Cumulative lifetime incidence } \\
\text { of DSM-IV diagnoses }\end{array}$ & $\begin{array}{l}\text { No } \\
\text { SAD } \\
\% w\end{array}$ & \multicolumn{3}{|c|}{ Symptomatic SAD } & \multicolumn{3}{|c|}{ 'Subthreshold' SAD } & \multicolumn{3}{|c|}{ DSM-IV SAD } \\
\hline Panic attack & 5.8 & 8.8 & 1.3 & $0.5-3.3$ & 10.8 & 1.7 & $0.8-3.5$ & 32.7 & $7.2 *$ & $2.4-21.1$ \\
\hline Panic disorder & 0.6 & 3.0 & 4.0 & $0.7-21.1$ & 4.0 & $5.6^{*}$ & $1.5-20.6$ & 23.9 & $51.2 *$ & $11.9-220.3$ \\
\hline Agoraphobia without panic & 2.5 & 6.4 & 2.4 & $0.8-7.1$ & 5.7 & 2.1 & $0.7-5.8$ & 3.8 & $1.5^{\mathrm{g}}$ & $0.1-11.7$ \\
\hline Social phobia & 6.4 & 5.2 & 0.8 & $0.2-2.6$ & 12.2 & 1.9 & $0.9-4.0$ & 19.2 & 3.4 & $0.8-13.6$ \\
\hline Specific phobia & 17.8 & 24.5 & 1.3 & $0.7-2.3$ & 29.2 & $1.7 *$ & $1.01-2.8$ & 42.8 & $13.1 *$ & $1.03-9.2$ \\
\hline GAD & 1.1 & 0 & n.e. & & 1.0 & 0.8 & $0.0-6.4$ & 11.4 & $10.8 * \mathrm{~g}$ & $1.8-61.4$ \\
\hline PTSD & 0.8 & 0 & n.e. & & 0.8 & 0.9 & $0.0-8.4$ & 13.5 & $17.5 * \mathrm{~g}$ & $3.2-95.1$ \\
\hline OCD & 0.8 & 0 & n.e. & & 0.7 & 0.7 & $0.0-7.1$ & 8.8 & $10.2 * \mathrm{~g}$ & $1.1-86.2$ \\
\hline Any anxiety disorder ${ }^{b}$ & 30.5 & 38.6 & 1.2 & $0.7-2.1$ & 43.0 & 1.5 & $0.9-2.4$ & 61.2 & $13.3 *$ & $1.1-10.0$ \\
\hline Any affective disorder ${ }^{\mathrm{c}}$ & 19 & 17.4 & 0.8 & $0.4-1.6$ & 28.4 & 1.6 & $0.9-2.6$ & 60.4 & $16.2 *$ & $2.0-18.8$ \\
\hline \multicolumn{11}{|l|}{ Substance use disorders } \\
\hline Nicotine dependence & 23.1 & 28.1 & 0.3 & $0.7-2.3$ & 29.6 & 1.4 & $0.8-2.2$ & 29.7 & 1.4 & $0.4-4.7$ \\
\hline Alcohol abuse & 20.9 & 17.5 & 1.0 & $0.5-2.0$ & 15.3 & 0.8 & $0.4-1.6$ & 7.3 & $0.3^{\mathrm{g}}$ & $0.0-2.7$ \\
\hline Alcohol dependence & 6.4 & 8.8 & 1.9 & $0.7-4.6$ & 11.3 & $2.3 *$ & $1.0-5.2$ & 27.9 & $17.7 *$ & $1.8-32.7$ \\
\hline Illegal drug abuse/dependence & 10.7 & 7.9 & 0.9 & $0.3-2.3$ & 5.7 & 0.6 & $0.2-1.5$ & 26.1 & 3.7 & $0.7-19.1$ \\
\hline Any substance use disorder & 40.3 & 47.7 & $1.6^{*}$ & $1.01-2.7$ & 41.6 & 1.2 & $0.7-1.9$ & 61.1 & 2.9 & $0.9-8.6$ \\
\hline Pain disorder ${ }^{\mathrm{d}}$ & 8.4 & 14.0 & 1.4 & $0.6-3.1$ & 16.7 & 1.8 & $0.9-3.5$ & 33.3 & $4.9 *$ & $1.5-15.7$ \\
\hline Any eating disorder ${ }^{\mathrm{e}}$ & 2.6 & 3.9 & 1.1 & $0.3-4.2$ & 5.8 & 1.8 & $0.6-5.3$ & 13.5 & $4.8^{\mathrm{g}}$ & $0.9-24.1$ \\
\hline Any adult DSM-IV diagnosis ${ }^{\mathrm{f}}$ & 62.1 & 74.9 & $2.2 *$ & $1.03-3.1$ & 77.2 & $2.6^{*}$ & $1.1-3.5$ & 89.8 & $12.5 *$ & $1.4-19.8$ \\
\hline
\end{tabular}

NOS = Not otherwise specified; $\% \mathrm{w}=$ weighted percentages; $\mathrm{OR}=$ odds ratios controlled for sex and age; n.e. = not estimable because of empty cells. $* \mathrm{p}<0.05$; cases in bold and italics indicate statistically significant associations.

${ }^{a}$ No SAD represents the reference group without any symptoms of SAD.

${ }^{\mathrm{b}}$ Includes panic disorder, agoraphobia, social phobia with or without impairment, any specific phobia with and without impairment, GAD, PTSD, and OCD.

${ }^{\mathrm{c}}$ Includes bipolar I, bipolar II, major depression and dysthymia.

${ }^{\mathrm{d}}$ Since we had no case with somatization disorder or hypochondriasis and only few cases with dissociative and conversion disorder in the entire sample, we did the analyses only for pain disorder and not for any somatoform disorder.

${ }^{\mathrm{e}}$ Includes anorexia, atypical anorexia, bulimia and atypical bulimia.

${ }^{\mathrm{f}}$ Includes nicotine dependence and social/specific phobia cases who do not meet the impairment criterion.

$\mathrm{g}$ These associations are based on a small number of comorbid cases $(\leq 2)$.

0.7-6.0). Subthreshold SAD predicted the onset of bipolar disorder type II $(\mathrm{HR}=8.1,95 \% \mathrm{CI}=2.3-27.4)$ but not of bipolar disorder type I $(\mathrm{HR}=0.6 ; 95 \% \mathrm{CI}=0.0$ 4.0) or major depression ( $\mathrm{HR}=1.5,95 \% \mathrm{CI}=0.9-2.5)$.

Substance Use Disorders. Threshold SAD was associated with subsequent alcohol dependence $(\mathrm{HR}=4.7$, $95 \% \mathrm{CI}=1.7-12.4)$ but not with alcohol abuse $(\mathrm{HR}=$ $0.5,95 \% \mathrm{CI}=0.0-2.8)$. A comparable pattern of results was found for subthreshold SAD (alcohol dependence:
$\mathrm{HR}=2.1,95 \% \mathrm{CI}=1.1-4.1 ;$ alcohol abuse: $\mathrm{HR}=0.9$, $95 \% \mathrm{CI}=0.5-1.6)$. Prior SAD did not predict nicotine dependence (threshold SAD: $\mathrm{HR}=1.3,95 \% \mathrm{CI}=0.4$ 3.5; subthreshold SAD: $\mathrm{HR}=1.3,95 \% \mathrm{CI}=0.8-2.0$ ) or illegal substance use disorders (threshold $\mathrm{SAD}: \mathrm{HR}=2.7$, $95 \% \mathrm{CI}=0.7-9.5$; subthreshold $\mathrm{SAD}, \mathrm{HR}=0.5,95 \%$ $\mathrm{CI}=0.1-1.3)$.

Somatoform Disorders. The risk of subsequent pain disorder was significantly increased among subjects with 
threshold SAD $(\mathrm{HR}=3.5,95 \% \mathrm{CI}=1.3-9.1)$ and to a lesser extent also among subjects with subthreshold SAD $(\mathrm{HR}=1.9,95 \% \mathrm{CI}=1.01-3.5)$.

Figure 2 shows age-specific cumulative lifetime incidences of major groups of mental disorders in subjects with prior DSM-IV SAD versus in subjects without prior DSM-IV SAD. For example, an HR of 2.4 for any subsequent mental disorder indicates a 2.4 -fold risk of mental disorders if threshold SAD had ever been present before.

Strictly Prospective Analyses. We further tested whether we obtain the same pattern of results with strictly prospective analyses which are presumably less biased by retrospective age-of-onset reports. For that, respondents who had already had the respective outcome disorder by the time SAD was assessed (at T0 or T1) were excluded from the analyses. In order to increase statistical power, we combined subthreshold and threshold SAD cases into one group. These analyses indicated that SAD predicted the first onset of bipolar type II disorder (OR $=9.9,95 \%$ $\mathrm{CI}=1.1-83.5)$, alcohol dependence $(\mathrm{OR}=3.3,95 \%$ $\mathrm{CI}=1.06-10.2)$, pain disorder $(\mathrm{OR}=2.9,95 \% \mathrm{CI}=1.2$ 6.6), and panic attack $(\mathrm{OR}=3.7,95 \% \mathrm{CI}=1.1-11.6)$ during the follow-up period from T1 to T2. SAD cases also had higher odds of developing a first-time PDAG compared to respondents without subthreshold or threshold $\mathrm{SAD}$, although this association did not reach statistical significance $(\mathrm{OR}=13.1,95 \% \mathrm{CI}=0.7-216.0)$. The association of SAD with GAD and OCD was not calculable because of empty cells.

\section{Gender Effects}

There was a significant interaction between subthreshold SAD and gender for the risk of major depression (HR for interaction $=6.0,95 \% \mathrm{CI}=1.2-28.1)$. In separate analyses, the HR of major depression associated with prior subthreshold SAD was 2.1 for females $(95 \% \mathrm{CI}=1.2$ 3.6 ) and 0.3 for males $(95 \% \mathrm{CI}=0.0-1.6)$. Because of empty cells, the interaction between threshold SAD and gender was not calculable for PDAG, agoraphobia, GAD, PTSD, OCD, and bipolar disorders.

\section{Is the Association between SAD and Subsequent}

Psychopathology Due to Other Comorbid Disorders?

To examine the extent to which the association between SAD and subsequent mental disorders might be explained by other DSM-IV disorders occurring prior to SAD, we additionally included mental disorders occurring prior to $\mathrm{SAD}$ as control variables into the Cox proportional hazard model. For threshold SAD, the pattern of significant results remained largely stable; only the association between SAD and any anxiety disorders lost statistical significance $(\mathrm{HR}=2.5,95 \% \mathrm{CI}=0.9-6.6)$. For subthreshold SAD, the association with alcohol dependence $(\mathrm{HR}=1.9,95 \% \mathrm{CI}=0.9-3.9)$ and with pain disor$\operatorname{der}(\mathrm{HR}=1.8,95 \% \mathrm{CI}=0.9-3.3)$ did not remain statistically significant, although the point estimates did not change considerably.

Is PDAG a Mediator for the Association between SAD and Subsequent Psychopathology?

Addressing the question of whether the relation between SAD and subsequent disorders might be mediated by PDAG, we adjusted the associations for PDAG in addition to mental disorders occurring prior to SAD. Threshold SAD was still strongly related to subsequent PTSD $(\mathrm{HR}=6.1,95 \% \mathrm{CI}=2.0-18.2), \mathrm{OCD}(\mathrm{HR}=8.6,95 \%$ $\mathrm{CI}=2.6-28.2)$, any bipolar disorder $(\mathrm{HR}=6.4,95 \%$ $\mathrm{CI}=2.3-17.8)$, and alcohol dependence $(\mathrm{HR}=3.5,95 \%$ $\mathrm{CI}=1.02-12.1)$, whereas the association with specific phobia $(\mathrm{HR}=2.7,95 \% \mathrm{CI}=0.8-8.6)$, GAD $(\mathrm{HR}=4.8$, $95 \% \mathrm{CI}=0.6-34.4)$, and pain disorder $(\mathrm{HR}=2.5,95 \%$ $\mathrm{CI}=0.8-7.3)$ lost statistical significance, although the point estimates remained largely unaltered. Changes in the HR attributable to PDAG ranged between 4\% (specific phobia) and 33.3\% (GAD). Likewise, prior subthreshold SAD was still associated with bipolar type II disorder $(\mathrm{HR}=8.5,95 \% \mathrm{CI}=2.3-30.7)$.

\section{Discussion}

Previous research has proposed at least three competing theories about the outcome of childhood SAD: (1) SAD is a specific risk factor for adult PDAG [2, 4]; (2) SAD is a general risk factor for adult anxiety disorders [18], and (3) SAD continues into adulthood [38]. The findings of the present study extend the nonspecific hypothesis by showing that the outcome of SAD goes well

Fig. 2. Cumulative lifetime incidences of DSM-IV mental disorders by the presence of prior DSM-IV SAD $(n=1,090)$. HRs are adjusted for age and sex. a Any DSM-IV mental disorder (also includes social and specific phobia cases who do not meet the impairment criterion). b Any anxiety disorder (also includes social and specific phobia cases who do not meet the impairment criterion). c Any affective disorder. d Any bipolar disorder. e Any substance use disorder (includes nicotine dependence). f Any somatoform disorder. 

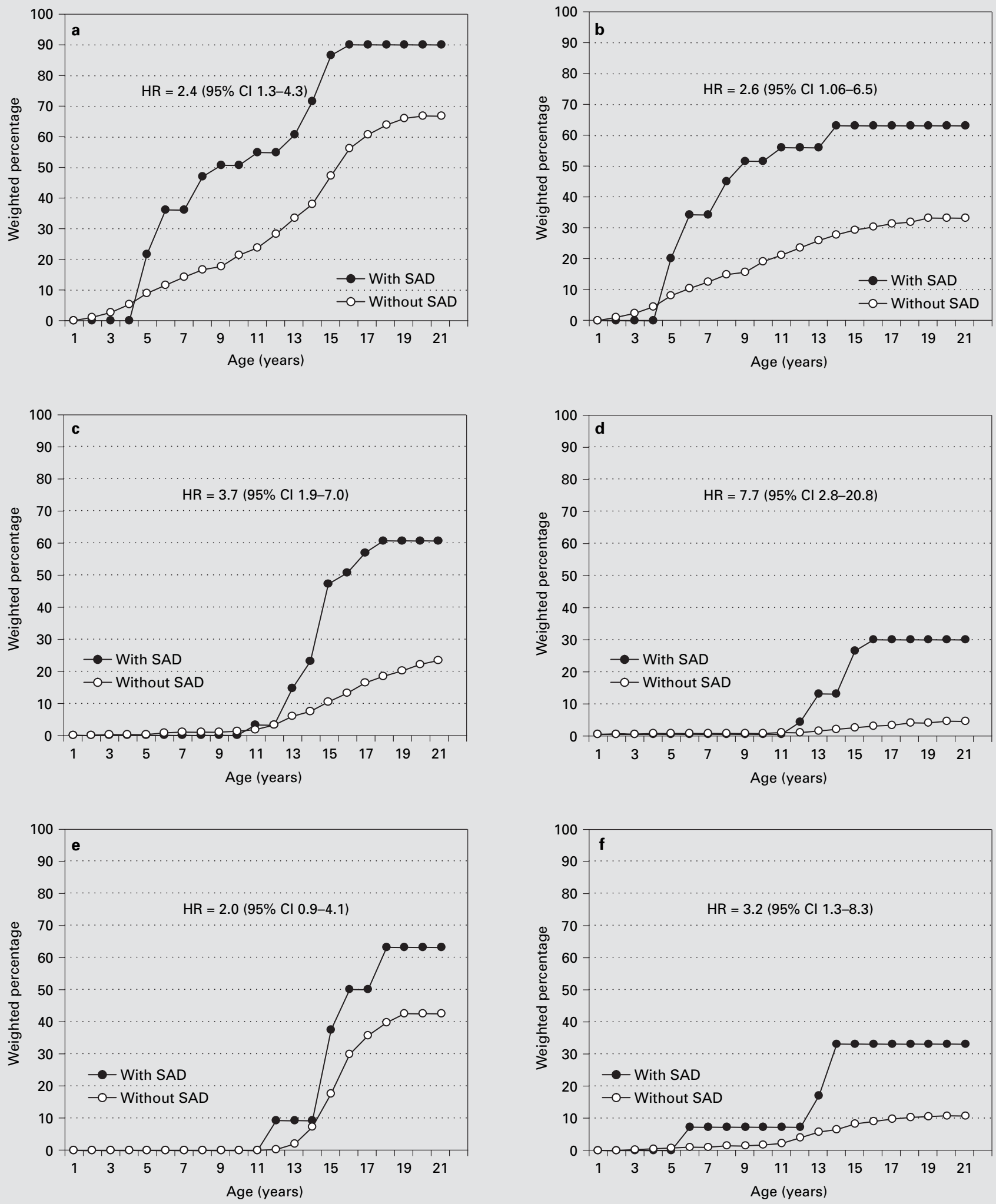
beyond anxiety disorders. First, cross-sectional comorbidity analyses reveal a considerable degree of lifetime comorbidity between SAD and a wide range of other mental disorders. Second, analyses taking into account the temporal order of mental disorders show that prior SAD is associated with increased risk not only for subsequent PDAG but also for bipolar disorders, alcohol dependence, and pain disorder. Third, strictly prospective analyses indicate that SAD is indeed a risk factor [39] for the development of panic attacks, bipolar disorder, alcohol dependence and pain disorder, and thus confirm the above-mentioned temporally directed associations which were based on retrospective age-of-onset reports.

\section{Association between SAD and Anxiety Disorders}

Our results show a strong association between SAD and PDAG; however, they also suggest associations with other anxiety disorders including specific phobia, PTSD, $\mathrm{OCD}$ and GAD. One may argue that the relationship between SAD and a wide range of anxiety disorders is attributable to comorbidity with PDAG. However, adjusting the associations for PDAG showed that PDAG only partly mediated the association between SAD and subsequent specific phobia and GAD but not on OCD and PTSD.

Thus, the present study confirms in a general population sample previous findings from clinical [14, 16-19] and nonclinical convenience samples [22] suggesting that childhood SAD carries a risk for several anxiety disorders rather than for PDAG alone. Furthermore, it indicates that the association between SAD and other anxiety disorders is not entirely attributable to comorbidity with PDAG. However, it has to be kept in mind that the results in regard to PTSD, OCD and GAD are based on a small number of cases and thus need to be replicated with larger samples.

\section{Association between SAD and Mental Disorders}

\section{Other than Anxiety Disorders}

One finding that warrants particular attention is the strong association between SAD and bipolar disorders, as only two studies have so far reported an SAD-bipolar link $[40,41]$. It is notable that in the latter clinical trial the highest rate of childhood SAD was found among bipolar patients with an additional PDAG diagnosis (50\%) and that this rate was considerably higher than among pure bipolar (25.8\%) and pure PDAG patients (4.2\%). Some authors have proposed that bipolar illness that co-occurs with panic may be a more homogeneous genetic subtype of bipolar disorder $[42,43]$. Considering that in our study
SAD was related to PDAG and bipolar disorder, it could be speculated that SAD is an early indicator of such a genetic vulnerability. However, this is rather speculative and further studies are needed to explore the genetic basis of SAD comorbid with bipolar disorder.

The finding that SAD is related to alcohol dependence seems to be in contrast to another community study showing that symptoms of GAD, but not of SAD, predicted the initiation of alcohol use during a 4-year follow-up period in a sample of children who were 9,11 , or 13 years at baseline [44]. One explanation for the discrepancy might be the older age of our sample. Children with SAD might start later with the consumption of alcohol, but might progress more rapidly to heavy use and dependence once they have started.

The present results also show an association between SAD and first onset of pain disorder, which has never been reported before; they further indicate that parts of this association are attributable to comorbid PDAG. Thus, this result is consistent with previous findings (a) from the EDSP showing linkages between anxiety disorders and somatoform complaints [45] and between PDAG and pain disorder [46] and (b) from other studies revealing a link between SAD and somatic pain $[47,48]$.

Although results from other studies [13, 24, 49] suggest an association between SAD and depression, in our study this association was evident only in females with subthreshold SAD. These findings may indicate different pathways for the development of mental disorders in males and females.

\section{Limitations}

Although some respondents reported current SAD, one limitation of the present study is the retrospective assessment of SAD. Subjects may have forgotten early and less impairing forms of SAD. SAD diagnoses might also be influenced by current psychopathology. Both types of recall biases could have led to an overestimation of the association of SAD with other mental disorders.

Evidence exists that the absolute dating of symptom onset is rather unreliable in retrospective studies [50]. Thus, the retrospective age-of-onset reports on which the temporal order between mental disorders in Cox regressions was based is another limitation.

The lack of diagnostic information from the parents is another shortcoming, although some evidence exists that the adolescent might be the better informant for diagnosing SAD [51].

Despite the fact that $84 \%$ of the baseline sample completed $\mathrm{T} 2$, our data reveal some selective attrition because 
a baseline lifetime diagnosis of nicotine dependence, illegal drug dependence, dysthymia, and specific phobia predicted dropout between $\mathrm{T} 0$ and $\mathrm{T} 2$. Considering that the majority of our sample had a relatively high socioeconomic status, these findings may not be generalizable to other populations.

Given that not all respondents have passed through the entire risk period for mental disorders, the results cannot yet be considered robust. However, 'false-negative cases' (i.e. cases that have not yet developed the outcome under consideration) probably lead to underestimation rather than to overestimation of associations.

\section{Conclusions}

Our results do not support a specific SAD-PDAG link as proposed by Klein [2]. PDAG was neither a specific outcome nor was it a complete mediator variable of SAD. SAD rather seems to be an important nonspecific risk factor for various mental disorders. On the basis of Manassis and Bradley's [52] etiological model of childhood anxiety disorders, it could be hypothesized that difficulties in affect modulation mediate the effect of SAD on various subsequent disorders. However, further studies are needed to explore the mechanisms behind the association of SAD with subsequent mental disorders.

\section{Acknowledgments}

This work is part of the Early Developmental Stages of Psychopathology Study (EDSP) and is funded by the German Ministry of Research and Technology, project No. 01 EB 9405/6 and 01 EB 9901/6, EB 01016200 and 01 EB 0440. Part of the field work and analyses were also additionally supported by grants of the Deutsche Forschungsgemeinschaft (DFG) LA1148/1-1 and WI2246/1-1. Principal investigators are Dr. Hans-Ulrich Wittchen and Dr. Roselind Lieb. Current or former staff members of the EDSP group are Dr. Kirsten von Sydow, Dr. Gabriele Lachner, Dr. Axel Perkonigg, Dr. Peter Schuster, Dr. Franz Gander, Dipl.-Stat. Michael Höfler, and Dipl.-Psych. Holger Sonntag, as well as Dipl.-Psych. Tanja Brückl, Mag. phil. Esther Beloch, Dr. Martina Fuetsch, Dipl.Psych. Elzbieta Garczynski, Dipl.-Psych. Alexandra Holly, Dr. Barbara Isensee, Dr. Marianne Mastaler, Dipl.-Psych. Agnes Nocon, Dr. Chris Nelson, Dipl.-Inf. Hildegard Pfister, Dr. Victoria Reed, Dipl.-Soz. Barbara Spiegel, Dipl.-Psych. Lena Schwender, Dipl.Psych. Andrea Schreier, Dipl.-Psych. Dilek Türk, Dipl.-Psych. Antonia Vossen, Dr. Ursula Wunderlich, and Dr. Petra Zimmermann. Scientific advisors are Dr. Jules Angst (Zurich), Dr. Jürgen Margraf (Basel), Dr. Günther Esser (Potsdam), Dr. Kathleen Merikangas (NIMH, Bethesda), Dr. Ron Kessler (Harvard, Boston) and Dr. Jim van Os (Maastricht).

\section{References}

$\checkmark 1$ Silove D, Manicavasagar V, Curtis J, Blaszczynski A: Is early separation anxiety a risk factor for adult panic disorder? A critical review. Compr Psychiatry 1996;37:167-179.

2 Klein DF: Delineation of two drug-responsive anxiety syndromes. Psychopharmacologia 1964;5:397-408.

3 Gittelman-Klein R: Is panic disorder associated with childhood separation anxiety disorder? Clin Neuropharmacol 1995;18:7-14.

4 Bowlby J: Attachment and Loss. London, The Hogarth Press, 1973, vol 2.

$\checkmark 5$ Klein D: Anxiety reconceptualized. Compr Psychiatry 1980;21:411-427.

6 American Psychiatric Association: Diagnostic and Statistical Manual of Mental Disorders, ed 3. Washington, American Psychiatric Association, 1994.

7 Ayuso JL, Alfonso S, Rivera A: Childhood separation anxiety and panic disorder: a comparative study. Prog Neuropsychopharmacol Biol Psychiatry 1989;13:665-671.

8 Balon R, Yeragani VK, Pohl R: Higher frequency of separation in panic disorder patients. Am J Psychiatry 1989;146:1351.
-9 Battaglia M, Bertella S, Politi E, Bernardeschi L, Perna G, Gabriele A, Bellodi L: Age of onset of panic disorder: influence of familial liability to the disease and of childhood separation anxiety disorder. Am J Psychiatry 1995;152: 1362-1364.

10 Gittelman R, Klein DF: Relationship between separation anxiety and panic and agoraphobic disorders. Psychopathology 1984;17(suppl 1):56-65.

$\checkmark 11$ Zitrin CM, Ross DC: Early separation anxiety and adult agoraphobia. J Nerv Ment Dis 1988; 176:621-625.

12 van der Molen GM, van den Hout MA, van Dieren AC, Griez E: Childhood separation anxiety and adult-onset panic disorders. J Anxiety Disord 1989;3:97-106.

$\checkmark 13$ Yeragani VK, Meiri PC, Balon R, Patel H, Pohl R: History of separation anxiety in patients with panic disorder and depression and normal controls. Acta Psychiatr Scand 1989; 79:550-556.

14 Raskin M, Peeke HV, Dickman W, Pinsker H: Panic and generalized anxiety disorders. Arch Gen Psychiatry 1982;39:687-689.

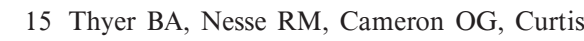
GC: Agoraphobia: a test of the separation anxiety hypothesis. Behav Res Ther 1985;23:7578.

16 Thyer BA, Nesse RM, Curtis GC, Cameron OG: Panic disorder: a test of the separation anxiety hypothesis. Behav Res Ther 1986;24: 209-211.

17 Silove D, Manicavasagar V, O'Connell D, Blaszczynski A: Reported early separation anxiety symptoms in patients with panic and generalised anxiety disorders. Aust NZ J Psychiatry 1993;27:489-494.

18 Lipsitz JD, Martin LY, Mannuzza S, Chapman TF, Liebowitz MR, Klein DF, Fyer AJ: Childhood separation anxiety disorder in patients with adult anxiety disorders. Am J Psychiatry 1994;151:927-929.

19 Aschenbrand SG, Kendall PC, Webb A, Safford SM, Flannery-Schroeder E: Is childhood separation anxiety disorder a predictor of adult panic disorder and agoraphobia? A seven-year longitudinal study. J Am Acad Child Adolesc Psychiatry 2003;42:1478-1485. 
20 Silove D, Manicavasagar V: Adults who feared school: is early separation anxiety specific to the pathogenesis of panic disorder? Acta Psychiatr Scand 1993;88:385-390.

-21 Silove D, Harris M, Morgan A, Boyce P, Manicavasagar V, Hadzi-Pavlovic D, Wilhelm K: Is early separation anxiety a specific precursor of panic disorder-agoraphobia? A community study. Psychol Med 1995;25:405-411.

$\checkmark 22$ Silove D, Manicavasagar V, Drobny J: Brief report: associations between juvenile and adult forms of separation anxiety disorder: a study of adult volunteers with histories of school refusal. J Nerv Ment Dis 2002;190:413-415.

-23 Pine DS, Cohen P, Gurley D, Brook J, Ma Y: The risk for early-adulthood anxiety and depressive disorders in adolescents with anxiety and depressive disorders. Arch Gen 1998;55: 56-64.

-24 Foley DL, Pickles A, Maes HM, Silberg JL, Eaves LJ: Course and short-term outcomes of separation anxiety disorder in a community. J Am Acad Child Adolesc Psychiatry 2004;43: 452-460.

-25 Wittchen H-U, Perkonigg A, Lachner G, Nelson CB: Early developmental stages of psychopathology study (EDSP): objectives and design. Eur Addict Res 1998;4:18-27.

-26 Lieb R, Isensee B, von Sydow K, Wittchen H$\mathrm{U}$ : The early stages of psychopathology study (EDSP): a methodological update. Eur Addict Res 2000;6:170-182.

27 Wittchen H-U, Pfister H (eds): DIA-X-Interviews: Manual für Screening-Verfahren und Interview; Interviewheft Längsschnittuntersuchung (DIA-X-Lifetime); Ergänzungsheft (DIA-X-Lifetime); Interviewheft Querschnittuntersuchung (DIA-X-12 Monate); Ergänzungsheft (DIA-X-12 Monate); PC-Programm zur Durchführung des Interviews (Längs- und Querschnittuntersuchung). Auswertungsprogramm. Frankfurt, Swets \& Zeitlinger, 1997.

-28 Lachner G, Wittchen H-U, Perkonigg A, Holly A, Schuster P, Wunderlich U, Türk D, Garczynski E, Pfister H: Structure, content and reliability of the Munich-Composite International Diagnostic Interview (M-CIDI). Substance use sections. Eur Addict Res 1998; 4:28-41.

29 Reed V, Gander F, Pfister H, Steiger A, Sonntag $\mathrm{H}$, Trenkwalder C, Hundt W, Wittchen H-U: To what degree does the Composite International Diagnostic Interview (CIDI) correctly identify DSM-IV disorders? Testing validity issues in a clinical sample. Int $\mathrm{J}$ Methods Psychiatr Res 1998;7:142-155.
30 Wittchen H-U, Lachner G, Wunderlich U, Pfister H: Test-retest reliability of the computerized DSM-IV version of the Munich-Composite International Diagnostic Interview (MCIDI). Soc Psychiatry Psychiatr Epidemio 1998;33:568-578.

31 Wittchen H-U, Lieb R, Schuster P, Oldehinkel $\mathrm{T}$ : When is onset? Investigations into early developmental stages of anxiety and depressive disorders; in Rapoport JL (ed): Childhood Onset of 'Adult' Psychopathology, Clinical and Research Advances. Washington, American Psychiatric Press, 1999, pp 259-302.

-32 Höfler M, Lieb R, Perkonigg A, Schuster P, Sonntag H, Wittchen H-U: Covariates of cannabis use progression in a representative population sample of adolescents: a prospective examination of vulnerability and risk factors. Addiction 1999;94:1679-1694.

33 Stata Corporation: Stata Statistical Software: Release 8.0. College Station, Stata Corporation, 2003.

34 Royall RM: Model robust confidence intervals using maximum likelihood estimators. Int Stat Rev 1986;54:221-226.

35 McCullagh P, Nelder JA: Generalized Linear Models, ed 2. London, Chapman \& Hall, 1989.

36 Therneau TM, Grambsch PM: Modeling Survival Data - Extending the Cox Model. Berlin, Springer, 2000.

37 Höfler M, Brückl T, Lieb R, Wittchen H-U: Calculating control variables with age at onset data to adjust for conditions prior to exposure. Soc Psychiatry Psychiatr Epidemiol 2005;40 731-736.

38 Manicavasagar V, Silove D, Franzcp JC, Wagner R: Continuities of separation anxiety from early life into adulthood. J Anxiety Disord 2000;14:1-18.

39 Kraemer HC: Current concepts of risk in psychiatric disorders. Curr Opin Psychiatry 2003 16:421-430.

40 Lewinsohn PM, Zinbarg R, Seeley JR, Lewinsohn M, Sack WH: Lifetime comorbidity among anxiety disorders and between anxiety disorders and other mental disorders. J Anxiety Disord 1997;11:377-394

41 Pini S, Abelli M, Mauri M, Muti M, Iazzetta P, Banti S, Cassano GB: Clinical correlates and significance of separation anxiety in patients with bipolar disorder. Bipolar Disord 2005; 7 : 370-376.
42 MacKinnon DF, McMahon FJ, Simpson SG, McInnis MG, DePaulo JR: Panic disorder with familial bipolar disorder. Biol Psychiatry 1997;42:90-95.

43 MacKinnon D, Xu J, McMahon F, Simpson S, Stine O, McInnis M, DePaulo J: Bipolar disorder and panic disorder in families: an analysis of chromosome 18 data. Am J Psychiatry 1998; 155:829-831.

-44 Kaplow JB, Curran PJ, Angold A, Costello EJ: The prospective relation between dimensions of anxiety and the initiation of adolescent alcohol use. J Clin Child Psychology 2001;30: 316-326.

45 Lieb R, Zimmermann P, Friis RH, Höfler M, Tholen S, Wittchen H-U: The natural course of DSM-IV somatoform disorders and syndromes among adolescents and young adults: a prospective-longitudinal study. Eur Psychiatry 2002; 17:321-331.

46 Lieb R, Pfister H, Mastaler M, Wittchen H-U: Somatoform syndromes and disorders in a representative population sample of adolescents and young adults: prevalence, comorbidity and impairments. Acta Psychiatr Scand 2000;101: 194-208.

47 Livingston R, Taylor JL, Crawford SL: A study of somatic complaints and psychiatric diagnosis in children. J Am Acad Child Adolesc Psychiatry $1988 ; 27: 185-187$.

48 Egger HL, Costello EJ, Erkanli A, Angold A: Somatic complaints and psychopathology in children and adolescents: stomach aches, musculoskeletal pains, and headaches. J Am Acad Child Adolesc Psychiatry 1999;38:852-860.

49 Last CG, Petrin S, Hersen M, Kazdin AE: A prospective study of childhood anxiety disorders. J Am Acad Child Adolesc Psychiatry 1996;39:1502-1510.

50 Angold A, Erkanli A, Costello J, Rutter M: Precision, reliability and accuracy in the dating of symptom onsets in child and adolescent psychopathology. J Child Psychol Psychiatry 1996;37:657-664.

51 Schwab-Stone M, Shaffer D, Dulcan M, Jensen P, Fisher P, Bird H, Goodman S: Criterion validity of the NIMH Diagnostic Interview Schedule for Children Version 2.3 (DISC-2.3). J Am Acad Child Adolesc Psychiatry 1996;35: 878-888

52 Manassis K, Bradley S: The development of childhood anxiety disorders: toward an integrated model. J Appl Dev Psychol 1994;15: 345-366. 